\title{
Effect of Wujia Shenghua capsule on uterine bleeding following medically-induced incomplete abortion in rats during early pregnancy
}

\author{
HAIYANG LIU ${ }^{1 *}$, WEI MA ${ }^{1 *}$, QI LIU ${ }^{1}$, FASHAN WANG ${ }^{2}$, \\ LING CAO $^{1}$, TIENAN LI ${ }^{1}$, NING ZHANG ${ }^{1}$ and FANG GENG ${ }^{3}$ \\ ${ }^{1}$ College of Jiamusi, Heilongjiang University of Chinese Medicine, Harbin, Heilongjiang 150040; \\ ${ }^{2}$ Duoduo Pharmaceutical Co. Ltd., Jiamusi, Heilongjiang $154002 ;{ }^{3}$ College of Chemistry and Chemical Engineering, \\ Harbin Normal University, Harbin, Heilongjiang 150025, P.R. China
}

Received May 30, 2014; Accepted January 20, 2015

DOI: $10.3892 /$ etm.2015.2548

\begin{abstract}
The Wujia Shenghua capsule (WSC) is derived from Sheng-Hua-Tang, a well-known traditional Chinese medicine compound prescription that has been widely applied during the postpartum period in Chinese communities for a number of years. The aim of the present study was to investigate the effect of WSC on uterine bleeding following medically-induced incomplete abortion in rats during early pregnancy. Incomplete abortions were induced in Wistar rats during early pregnancy using mifepristone combined with misoprostol. The effects of WSC treatment were investigated in terms of the duration and volume of uterine bleeding, the uterine index and shape, and various hemodynamic indexes. In addition, blood samples were collected to measure the levels of estradiol $\left(\mathrm{E}_{2}\right)$, fibronectin $(\mathrm{FN})$ and laminin $(\mathrm{LM})$ via a radioimmunoassay or enzyme-linked immunosorbent assay, while the expression levels of FN, estrogen receptor (ER) and progesterone receptor (PR) in the uterine tissues were determined by immunohistochemistry. The in vivo results demonstrated that WSC treatment markedly shortened the duration and reduced the volume of uterine bleeding when compared with the model group. Furthermore, WSC treatment significantly elevated the $\mathrm{E}_{2}$ level in the serum and the expression of the ER and PR in
\end{abstract}

Correspondence to: Dr Ning Zhang, College of Jiamusi, Heilongjiang University of Chinese Medicine, 24 Heping Road, Harbin, Heilongjiang 150040, P.R. China

E-mail: zhengh56xiang@163.com

Dr Fang Geng, College of Chemistry and Chemical Engineering, Harbin Normal University, 1 Shida Road, Harbin, Heilongjiang 150025, P.R. China

E-mail: gengfang1980@163.com

${ }^{*}$ Contributed equally

Key words: Wujia Shenghua capsule, medical abortion, uterine bleeding, estrogen receptor, progesterone receptor the uterine tissues, while notably decreasing the FN and LM levels in the serum and uterine tissues. In addition, the hemodynamic indexes were shown to improve with WSC treatment. These results demonstrated that WSC exerted an inhibitory effect on the bleeding caused by medical abortion, possibly through modulating the $\mathrm{E}_{2}$, ER, PR, FN and LM levels.

\section{Introduction}

In a number of countries, a mifepristone plus misoprostol regimen is the most frequently used medical method for pregnancy termination in early gestation, with efficacy and safety demonstrated for early abortion. However, abnormal uterine bleeding is among the major limitations in such a regimen, and can lead to endometritis or infertility (1-3).

Sheng-Hua-Tang, a well-known traditional Chinese medicine (TCM) compound prescription, has been widely used during the postpartum period in Chinese communities for a number of years $(4,5)$. A previous study demonstrated that use of Sheng-Hua-Tang during the first month of the postpartum period may have a positive effect on female health-related quality of life (6). In addition, Shen-Hua-Tang administration was shown to significantly correlate with an anteverted uterus, and was effective for uterine contraction (7). The Wujia Shenghua capsule (WSC), which comprises Radix et Caulis Acanthopanacis Senticosi, Radix Angelicae Sinensis, Rhizoma Chuanxiong, Semen Persicae, Radix Glycyrrhizae and Rhizoma Zingiberis Preparata, is derived from Sheng-Hua-Tang, and has been shown to have beneficial effects in Chinese females following medically-induced abortions. These beneficial effects include a reduction in the bleeding volume, shortening the bleeding duration, promoting the blood flow and resolving the blood stasis (8). However, limited information from basic studies is available with regard to the mechanisms underlying the effects of WSC on abnormal uterine bleeding following medically-induced abortion.

Thus, the aim of the present study was to investigate the effect of WSC on abnormal uterine bleeding following a medically-induced abortion in rats, and also provide evidence for the mechanism of action. 


\section{Materials and methods}

Animals. A total of 32 eight-week-old female Wistar rats (weight, 180-220 g) were obtained from the Laboratory Animal Center of Heilongjiang University of Chinese Medicine (Harbin, China). The experimental protocols were conducted in accordance with the Guidelines for Animal Experiments (US Government Principle for the Utilization and Care of Vertebrate Animals Used in Testing, Research and Training) (9), and were approved by the Ethical Committee of Heilongjiang University of Chinese Medicine (no. SCXK Hei2008004).

WSC and reagents. WSC was purchased from Duoduo Pharmaceutical Co., Ltd. (Jiamusi, China); the enzyme-linked immunosorbent assay (ELISA) kit for estradiol $\left(\mathrm{E}_{2}\right)$ was obtained from Beijing Yuande Biomedical Engineering Co., Ltd. (Beijing, China); the radioimmunoassay (RIA) kit for laminin (LM) was purchased from Beijing North Institute of Biotechnology (Beijing, China); the ELISA kit for fibronectin (FN), rabbit polycolonal antibodies against LM (BA1033) and FN (BA1049), and the streptavidin-biotin complex (SABC) and 3,3'-diaminobenzidine (DAB) kits were all purchased from Boster Biological Technology, Ltd. (Wuhan, China); rabbit polycolonal antibodies against ER $\alpha$ (SC542), anti-ER $\beta$ (SC8974) and anti-PR (SC538) were purchased from Beijing Zhongshan Golden Bridge Biotechnology Co., Ltd. (Beijing, China); the mifepristone and misoprostol tablets were obtained from Beijing Zizhu Pharmaceutical Co., Ltd. (Beijing, China).

Model replication and groups. Female Wistar rats were mated with male rats of proven fertility in the evening, at a ratio of 2:1, as previously reported (10). If sperm was found in the vaginal smears the following morning, that day was considered as day 1 of gestation. On day 7 of gestation, 32 rats were randomly divided into four groups, which included the normal (group N), pregnant control (group P), model (group M) and WSC-treated (group W) groups, with eight rats in each group. Abortions were induced in each rat from groups $\mathrm{M}$ and $\mathrm{W}$ using $8.3 \mathrm{mg} / \mathrm{kg}$ mifepristone, followed by $100 \mu \mathrm{g} / \mathrm{kg}$ misoprostol 10 hours later, which were applied via intragastic administration. Cotton balls of the same weight, which were hemi-wrapped with plastic films, were subsequently placed into the vagina of the rats to verify the success of the abortion and to prevent blood leakage. From day 8 of gestation, the rats in groups N, P and M were treated with $1 \mathrm{ml}$ per $100 \mathrm{~g}$ body weight distilled water each day for seven days, whereas the rats in group $\mathrm{W}$ were treated with $1 \mathrm{ml}$ per $100 \mathrm{~g}$ body weight WSC suspension at a concentration of $0.25 \mathrm{~g} / \mathrm{ml}$ per day for seven days.

Uterine index measurement and hematoxylin-eosin staining. On day 14 of gestation, all the rats were anesthetized with ether and visceral organs were removed. The unilateral uterine specimens were weighed. The uterine indexes were subsequently calculated by dividing the uterine weight with the body weight of each rat. The specimens were fixed in 4\% formaldehyde for 24-48 h, embedded in paraffin, serially sectioned and restained with hematoxylin-eosin. Following incubation at $37^{\circ} \mathrm{C}$ and sealing with neutral gum, the uterine shape was investigated under a microscope (CX21; Olympus Corporation, Tokyo, Japan).
Duration and volume of uterine bleeding measurements. From day 8 of gestation, a new cotton ball was replaced in the vagina at an interval of $6 \mathrm{~h}$ from 6:00, until no blood stain was observed. The duration of uterine bleeding was recorded and the cotton balls were stored at $-20^{\circ} \mathrm{C}$ for the determination of the uterine bleeding volume. On day 14 of gestation, a $0.02-\mathrm{ml}$ blood sample was collected from the tail vein using a hemoglobin pipet, added to $4 \mathrm{ml}\left(\mathrm{V}_{1}\right) \mathrm{NaOH}$ solution (5\%) and mixed. The cotton balls from each rat were placed in a beaker, soaked and washed with the appropriate amount of $\mathrm{NaOH}$ solution that was adjusted to the quantity of bleeding. The washed solution was then preserved in an additional beaker. The process was repeated once or twice as required, and the total volume $\left(\mathrm{V}_{2}\right)$ of $\mathrm{NaOH}$ solution used was recorded. Following complete mixing of the washed solution, a $5-\mathrm{ml}$ sample of the mixture was filtrated using a filtrator (Beijing Bomei Glass Co., Ltd., Beijing, China). The absorbance (A) values of the filtered extract and the 4-ml NaOH solution containing the tail vein blood were recorded at $546 \mathrm{~nm}$ using an ultraviolet-visible light detector (Helios Gamma; Thermo Fisher Scientific, Waltham, MA, USA), with a $5 \% \mathrm{NaOH}$ solution used as the blank control. The volume of uterine bleeding was calculated using the following equation: Volume $(\mathrm{ml})=$ tail vein blood $(0.02 \mathrm{ml}) \times\left(\mathrm{A}\right.$ of filtered extract $\left.\mathrm{x} \mathrm{V}_{2}\right) /(\mathrm{A}$ of tail vein blood $\mathrm{x} \mathrm{V}_{1}$ ).

Determination of the serum $E_{2}, F N$ and LM levels. Blood samples were collected from the femoral artery of the rats on days 1, 8 and 14 of gestation. Following centrifugation at $600 \mathrm{x}$ g for $10 \mathrm{~min}$, the serum was aspirated and stored at $-20^{\circ} \mathrm{C}$. The $\mathrm{E}_{2}$ level was analyzed with an ELISA kit, according to the manufacturer's instructions. For the measurement of FN and LM levels, plasma samples were collected on day 14 of gestation and analyzed by ELISA and RIA, respectively, according to the manufacturer's instructions.

Immunohistochemistry. Paraffin-embedded tissues prepared for hematoxylin-eosin staining were also used in the immunohistochemistry assay. Tissue sections were blocked with $5 \%$ bovine serum albumin at $37^{\circ} \mathrm{C}$ for $30 \mathrm{~min}$, and incubated with primary rabbit polyclonal antibodies targeted against ER, PR, FN and LM at $4^{\circ} \mathrm{C}$ overnight. The samples were subsequently incubated with a biotin-conjugated secondary antibody (BST06K11A; Beijing Zhongshan Golden Bridge Biotechnology Co.,Ltd.). Staining was developed by incubation of the sections with the SABC and visualized using DAB. All the slides were counterstained with hematoxylin, and images were captured using an inverted microscope (magnification, x100) (IX71-21PH; Olympus Corporation). Immunoreactive spots from five randomly selected fields in each section were further selected for analysis and quantified using Image-Pro Plus 6.0 software (Media Cybernetics, Inc., Rockville, MD, USA).

Statistical analysis. The data are expressed as the mean \pm standard deviation. Statistical analyses were conducted using SPSS version 17.0 (SPSS Inc., Chicago, IL, USA). The statistical significance of differences was evaluated using the Mann-Whitney U-test, where $\mathrm{P}<0.05$ was considered to indicate a statistically significant difference. 
A

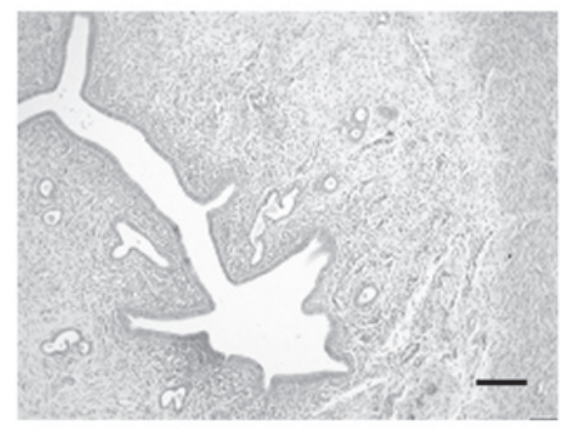

C



B

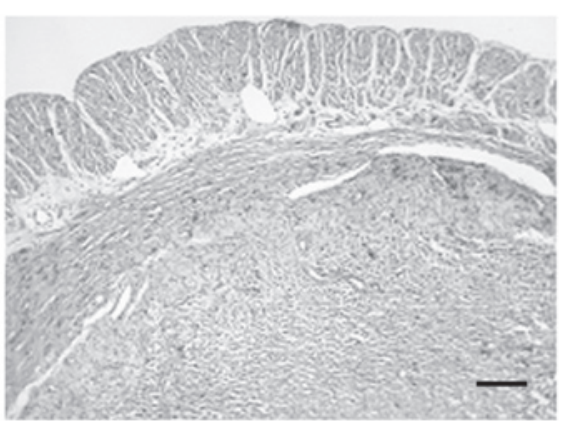

D

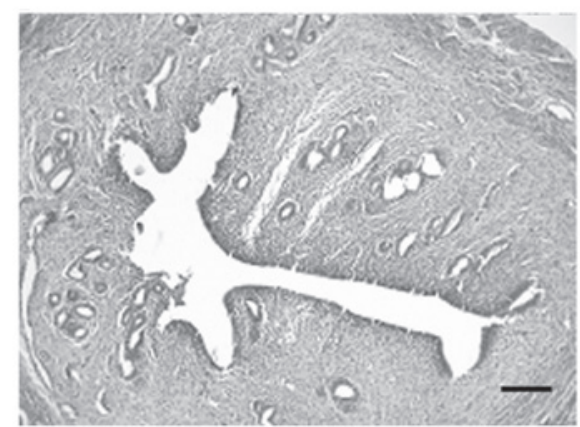

Figure 1. Hematoxylin and eosin staining of the uterine tissue in the (A) normal, (B) pregnant control, (C) model and (D) Wujia Shenghua capsule treatment groups (scale bar, $100 \mu \mathrm{m}$ ).

Table I. Effect of WSC on the uterine weight and uterine index.

\begin{tabular}{lcl}
\hline Group & Uterine weight $(\mathrm{g})$ & Uterine index \\
\hline $\mathrm{N}$ & $0.301 \pm 0.093$ & $0.0017 \pm 0.0007$ \\
$\mathrm{P}$ & $2.328 \pm 1.073$ & $0.0098 \pm 0.0051^{\mathrm{a}}$ \\
$\mathrm{M}$ & $1.312 \pm 0.787$ & $0.0058 \pm 0.0032^{\mathrm{b}}$ \\
$\mathrm{W}$ & $0.505 \pm 0.1776$ & $0.0021 \pm 0.0008^{\mathrm{c}}$ \\
\hline
\end{tabular}

Data are expressed as the mean \pm standard deviation $(\mathrm{n}=8) .{ }^{\mathrm{a}} \mathrm{P}<0.01$, vs. group $\mathrm{N}$; ${ }^{\mathrm{b}} \mathrm{P}<0.01$, vs. group $\mathrm{P}$; ${ }^{\mathrm{c}} \mathrm{P}<0.05$, vs. group $\mathrm{M}$. WSC, Wujia Shenghua capsule; N, normal; $\mathrm{P}$, pregnant control; $\mathrm{M}$, model; $\mathrm{W}$, WSC treatment.

\section{Results}

Effect of WSC on the uterine index and shape. As shown in Table I, the uterine indexes in groups $\mathrm{P}$ and $\mathrm{M}$ were significantly higher compared with that observed in group $\mathrm{N}(\mathrm{P}<0.01)$; whereas the uterine index in group $\mathrm{W}$ was notably lower when compared with group $\mathrm{M}(\mathrm{P}<0.05)$.

The pathological results obtained from the paraffin sections of the uterine tissue revealed that there were a number of trophoblastic cells observed in group $\mathrm{P}$ when compared with the normal uterine shape in group N. However, in group $\mathrm{M}$, there was a predominance of decidual cells and few trophocytes, in addition to evidence of extravasated blood. In group $\mathrm{W}$, there were few decidual cells observed and no evidence of extravasated blood (Fig. 1).

Effect of WSC on the duration and volume of uterine bleeding. No evidence of uterine bleeding was observed in groups $\mathrm{N}$ and $\mathrm{P}$. The duration of uterine bleeding was prolonged and the
Table II. Effect of WSC on the duration and volume of uterine bleeding.

\begin{tabular}{lcc}
\hline Group & $\begin{array}{c}\text { Volume of uterine } \\
\text { bleeding }(\mathrm{ml})\end{array}$ & $\begin{array}{c}\text { Duration of uterine } \\
\text { bleeding }(\mathrm{h})\end{array}$ \\
\hline $\mathrm{N}$ & $0.05 \pm 0.02$ & $0 \pm 0$ \\
$\mathrm{P}$ & $0.06 \pm 0.04$ & $0 \pm 0$ \\
$\mathrm{M}$ & $0.40 \pm 0.15^{\mathrm{a}}$ & $124.4 \pm 22.0^{\mathrm{a}}$ \\
$\mathrm{W}$ & $0.22 \pm 0.16^{\mathrm{b}}$ & $71.3 \pm 10.4^{\mathrm{c}}$ \\
\hline
\end{tabular}

${ }^{\mathrm{a}} \mathrm{P}<0.01$, vs. group $\mathrm{P} ;{ }^{\mathrm{b}} \mathrm{P}<0.05$ and ${ }^{\mathrm{c}} \mathrm{P}<0.01$, vs. group $\mathrm{M}$. WSC, Wujia Shenghua capsule; N, normal; P, pregnant control; M, model; W, WSC treatment.

volume of uterine bleeding increased significantly in group $\mathrm{M}$ when compared with group $\mathrm{P}(\mathrm{P}<0.01)$; whereas the duration of uterine bleeding was reduced and the volume of uterine bleeding decreased significantly in group $\mathrm{W}$ when compared with group $\mathrm{M}(\mathrm{P}<0.01$ and $\mathrm{P}<0.05$, respectively; Table II).

Effect of WSC on the serum $E_{2}$ level. Table III shows the $\mathrm{E}_{2}$ level in the rats from the various groups. No statistically significant changes were observed in the $\mathrm{E}_{2}$ level on days 1,8 and 14 of gestation in group $\mathrm{N}$. However, in group $\mathrm{P}$, the $\mathrm{E}_{2}$ level exhibited an increasing trend following the experimental days. In addition, the $\mathrm{E}_{2}$ level in group $\mathrm{M}$ increased initially at day 8 of gestation and then decreased by day 14 of gestation. The serum $\mathrm{E}_{2}$ level in group $\mathrm{W}$ was significantly elevated when compared with that in group $\mathrm{M}$ on day 14 of gestation $(\mathrm{P}<0.01)$.

Effect of WSC on the plasma levels of FN and LM. As shown in Table IV, the plasma levels of FN and LM in group M were 
Table III. Effect of WSC on the serum $\mathrm{E}_{2}$ level.

\begin{tabular}{lccc}
\hline & \multicolumn{3}{c}{$\mathrm{E}_{2}(\mathrm{pg} / \mathrm{ml})$} \\
\cline { 2 - 4 } Group & Day 1 & Day 8 & Day 14 \\
\hline $\mathrm{N}$ & $15.27 \pm 4.20$ & $14.98 \pm 7.14$ & $15.63 \pm 5.36$ \\
$\mathrm{P}$ & $15.52 \pm 3.90$ & $17.18 \pm 4.14$ & $18.23 \pm 4.87$ \\
$\mathrm{M}$ & $15.44 \pm 3.25$ & $33.03 \pm 9.62$ & $22.47 \pm 6.37^{\mathrm{a}}$ \\
$\mathrm{W}$ & $15.45 \pm 3.02$ & $34.89 \pm 5.72$ & $39.57 \pm 5.19^{\mathrm{b}, \mathrm{c}}$
\end{tabular}

${ }^{\mathrm{a}} \mathrm{P}<0.05$ and ${ }^{\mathrm{b}} \mathrm{P}<0.01$, vs. group $\mathrm{P}$; ${ }^{\mathrm{c}} \mathrm{P}<0.01$, vs. group $\mathrm{M}$. $\mathrm{E}_{2}$, estradiol; WSC, Wujia Shenghua capsule; N, normal; P, pregnant control; M, model; W, WSC treatment.

Table IV. Effect of WSC on the plasma levels of FN and LM.

\begin{tabular}{lcc}
\hline Group & FN $(\mathrm{pg} / \mathrm{ml})$ & $\mathrm{LM}(\mathrm{ng} / \mathrm{ml})$ \\
\hline $\mathrm{N}$ & $0.05 \pm 0.01$ & $12.44 \pm 4.32$ \\
$\mathrm{P}$ & $0.06 \pm 0.01$ & $13.57 \pm 6.52$ \\
$\mathrm{M}$ & $2.19 \pm 1.49^{\mathrm{b}}$ & $20.45 \pm 7.47^{\mathrm{a}}$ \\
$\mathrm{W}$ & $0.08 \pm 0.02^{\mathrm{d}}$ & $15.82 \pm 8.97^{\mathrm{c}}$ \\
\hline
\end{tabular}

${ }^{a} \mathrm{P}<0.05$ and ${ }^{\mathrm{b}} \mathrm{P}<0.01$, vs. group $\mathrm{P}$; ${ }^{\mathrm{C}} \mathrm{P}<0.05$ and ${ }^{\mathrm{d}} \mathrm{P}<0.01$, vs. group M. FN, fibronectin; LM, laminin; WSC, Wujia Shenghua capsule; N, normal; P, pregnant control; M, model; W, WSC treatment.

Table V. Effect of WSC on the expression of the ER, PR and $\mathrm{FN}$ in the uterine tissue (OD values).

\begin{tabular}{llcc}
\hline Group & \multicolumn{1}{c}{ ER $\alpha$} & \multicolumn{1}{c}{ PR } & FN \\
\hline $\mathrm{N}$ & $0.091 \pm 0.024$ & $0.076 \pm 0.022$ & $0.084 \pm 0.011$ \\
$\mathrm{P}$ & $0.095 \pm 0.019$ & $0.065 \pm 0.012$ & $0.104 \pm 0.020$ \\
$\mathrm{M}$ & $0.036 \pm 0.025^{\mathrm{b}}$ & $0.043 \pm 0.023^{\mathrm{a}}$ & $0.251 \pm 0.069^{\mathrm{a}}$ \\
$\mathrm{W}$ & $0.208 \pm 0.072^{\mathrm{d}}$ & $0.095 \pm 0.035^{\mathrm{c}}$ & $0.091 \pm 0.033^{\mathrm{d}}$ \\
\hline
\end{tabular}

${ }^{\mathrm{a}} \mathrm{P}<0.05$ and ${ }^{\mathrm{b}} \mathrm{P}<0.01$, vs. group $\mathrm{P}$; ${ }^{\mathrm{c}} \mathrm{P}<0.05$ and ${ }^{\mathrm{d}} \mathrm{P}<0.01$, vs. group $\mathrm{M}$. $\mathrm{ER}$, estrogen receptor; $\mathrm{PR}$, progesterone receptor; FN, fibronectin; WSC, Wujia Shenghua capsule; N, normal; P, pregnant control; M, model; W, WSC treatment.

significantly elevated when compared with group $\mathrm{P}(\mathrm{P}<0.01$ and $\mathrm{P}<0.05$, respectively). However, the levels of FN and LM in group $\mathrm{W}$ were markedly lower than that observed in group $\mathrm{M}$ $(\mathrm{P}<0.01$ and $\mathrm{P}<0.05$, respectively).

Effect of WSC on the expression levels of ER, PR and FN in the uterine tissues. Immunohistochemistry staining results showing the expression of the ER, PR and FN in the uterine tissues are shown in Fig. 2. Since no evident expression of LM was detected in the uterine tissue (data not shown), LM expression was not analyzed with immunohistochemistry. The $\mathrm{ER} \alpha$ and PR were predominately expressed in the endometrial glandular epithelial cells, simple columnar epithelial cells and were also detected in the smooth muscle cells of the uterine endometrium. No statistically significant differences were observed between the optical density (OD) values for the ER $\alpha$ and $\mathrm{PR}$ in groups $\mathrm{P}$ and $\mathrm{N}$. However, the OD values of the $\mathrm{ER} \alpha$ and $\mathrm{PR}$ were significantly decreased in group $\mathrm{M}$ when compared with group $\mathrm{P}(\mathrm{P}<0.01$ and $\mathrm{P}<0.05$, respectively), whereas the OD values of the ER $\alpha$ and PR were significantly increased in group $\mathrm{W}$ when compared with group $\mathrm{M}(\mathrm{P}<0.01$ and $\mathrm{P}<0.05$, respectively). $\mathrm{FN}$ was primarily expressed in the myometrial and endometrial interstitial cells and cells of the decidual tissues. No statistically significant difference was observed between the OD value of FN in groups $\mathrm{P}$ and $\mathrm{N}$. The OD value of FN was significantly increased in group $\mathrm{M}$ when compared with group $\mathrm{P}(\mathrm{P}<0.05)$, whereas the $\mathrm{OD}$ value of $\mathrm{FN}$ was significantly decreased in group $\mathrm{W}$ when compared with group $\mathrm{M}(\mathrm{P}<0.01$; Table $\mathrm{V})$.

Effect of WSC on the hemodynamic indexes. As shown in Table VI, no statistically significant differences were observed in the hemodynamic indexes when comparing groups $\mathrm{P}$ and $\mathrm{N}$. The plasma viscosity, the whole blood viscosity at shear rates of $1 \mathrm{mPa} \bullet \mathrm{s}$ and $5 \mathrm{mPa} \bullet$ s, the whole blood relative index (low shear) and the whole blood reduced viscosity (low shear) were significantly increased in group $\mathrm{M}$ when compared with group P; whereas the plasma viscosity, the whole blood viscosity at shear rates of $1 \mathrm{~s}^{-1}$ and $5 \mathrm{~s}^{-1}$, the whole blood relative index (low shear) and the whole blood reduced viscosity (low shear) were significantly decreased in group $\mathrm{W}$ when compared with group $\mathrm{M}$.

\section{Discussion}

In the present study, the beneficial effects of WSC, which is derived from Sheng-Hua-Tang, a well-known TCM compound prescription used during the postpartum period in females, were investigated on abnormal uterine bleeding. In addition, the underlying mechanisms were investigated using a rat model of medical abortion.

As demonstrated in the present study, when compared with the model group, WSC treatment was shown to markedly decrease the volume of uterine bleeding, reduce the duration of bleeding and the uterine index. Residual decidual tissues were found to be responsible for heavy and prolonged bleeding following the medical abortion, as previously reported (11-13), Histological examination revealed that little residual of the conceptus was present following WSC treatment. Therefore, the in vivo inhibitory effect of WSC on abnormal uterine bleeding may be associated with the promotion of residual discharge in the rat uterus.

$\mathrm{E}_{2}$ and the ER play an important role during the process of abnormal uterine bleeding by modulating the proliferation of endometrial epithelial and stromal cells and enhancing angiogenesis (14-17). The results of the present study demonstrated that WSC treatment significantly elevated the serum $\mathrm{E}_{2}$ level, while reducing the expression of the ER in the uterine tissues on day 14 of gestation, as compared with the model group. PR, as the main target of mifepristone (18), has been demonstrated to be involved in the regulation of abnormal uterine bleeding (19-22). In the present study, WSC treatment was also shown to markedly elevate PR expression 
Table VI. Effect of WSC on the hemodynamic indexes.

\begin{tabular}{|c|c|c|c|c|}
\hline Hemodynamic index & Group N & Group P & Group M & Group W \\
\hline Whole blood viscosity $(1 / \mathrm{s}, \mathrm{mPa} \bullet \mathrm{s})$ & $17.92 \pm 3.20$ & $18.79 \pm 4.36$ & $26.78 \pm 4.91^{\mathrm{a}}$ & $20.73 \pm 4.71^{\mathrm{c}}$ \\
\hline Whole blood viscosity $(5 / \mathrm{s}, \mathrm{mPa} \bullet \mathrm{s})$ & $8.88 \pm 1.06$ & $8.19 \pm 1.34$ & $10.71 \pm 1.38^{\mathrm{a}}$ & $9.02 \pm 1.51^{\mathrm{c}}$ \\
\hline Whole blood viscosity $(30 / \mathrm{s}, \mathrm{mPa} \bullet \mathrm{s})$ & $5.01 \pm 0.45$ & $5.02 \pm 0.69$ & $5.59 \pm 0.42$ & $5.13 \pm 0.57$ \\
\hline Whole blood viscosity $(200 / \mathrm{s}, \mathrm{mPa} \bullet \mathrm{s})$ & $3.85 \pm 0.29$ & $3.75 \pm 0.33$ & $3.92 \pm 0.17$ & $3.81 \pm 0.29$ \\
\hline Plasma viscosity (mPa•s) & $1.51 \pm 0.31$ & $1.52 \pm 0.14$ & $1.95 \pm 0.36^{\mathrm{b}}$ & $1.73 \pm 0.12^{\mathrm{c}}$ \\
\hline Erythrocyte sedimentation rate $(\mathrm{mm} / \mathrm{h})$ & $23.71 \pm 1.70$ & $24.00 \pm 4.19$ & $23.16 \pm 5.45$ & $23.25 \pm 3.94$ \\
\hline Hematocrit (1/1) & $0.31 \pm 0.01$ & $0.32 \pm 0.03$ & $0.35 \pm 0.03$ & $0.35 \pm 0.03$ \\
\hline Whole blood relative index (high shear) & $2.47 \pm 0.25$ & $2.48 \pm 0.24$ & $2.06 \pm 0.46$ & $2.31 \pm 0.38$ \\
\hline Whole blood relative index (low shear) & $11.52 \pm 2.21$ & $12.34 \pm 2.78$ & $15.72 \pm 2.81^{\mathrm{a}}$ & $11.74 \pm 1.08^{\mathrm{c}}$ \\
\hline Whole blood reduced viscosity (low shear) (mPa•s) & $51.75 \pm 8.59$ & $52.78 \pm 9.99$ & $73.98 \pm 14.26^{\mathrm{b}}$ & $59.51 \pm 5.09^{c}$ \\
\hline Whole blood reduced viscosity (high shear) (mPa $\bullet$ s) & $6.64 \pm 1.20$ & $6.93 \pm 0.60$ & $6.58 \pm 0.91$ & $6.57 \pm 0.53$ \\
\hline
\end{tabular}

${ }^{\mathrm{a}} \mathrm{P}<0.05$ and ${ }^{\mathrm{b}} \mathrm{P}<0.01$, vs. group $\mathrm{P}$; ${ }^{\mathrm{P}} \mathrm{P}<0.05$, vs. group M. WSC, Wujia Shenghua capsule; N, normal; $\mathrm{P}$, pregnant control; M, model; W, WSC treatment.

A

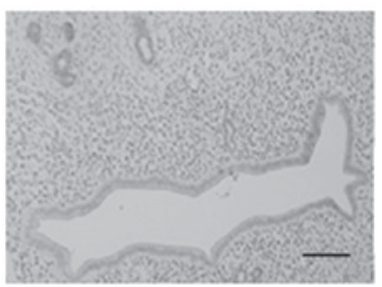

$\mathbf{E}$

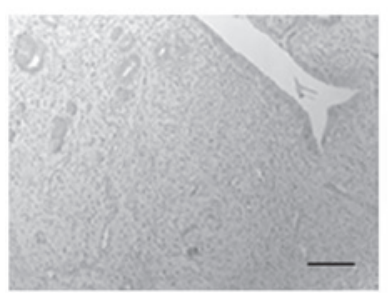

I

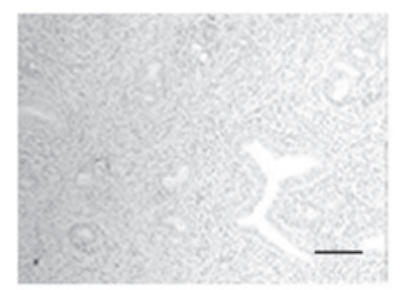

B

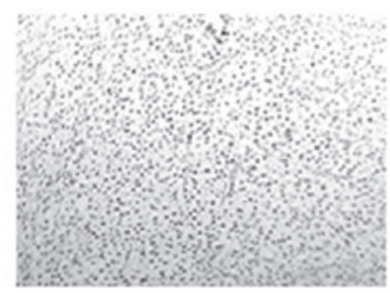

F

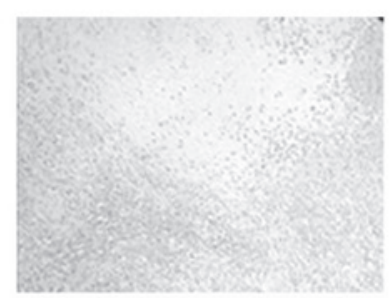

J

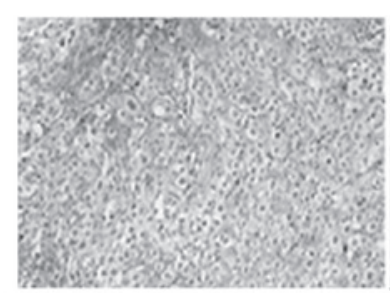

C

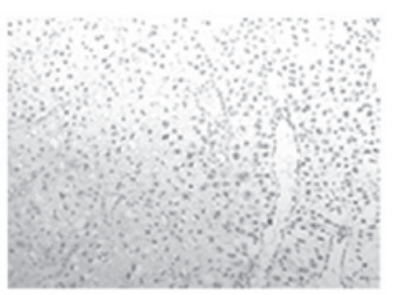

G

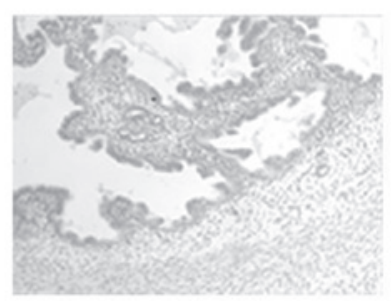

$\mathbf{K}$

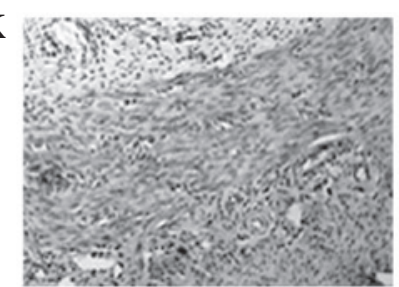

D

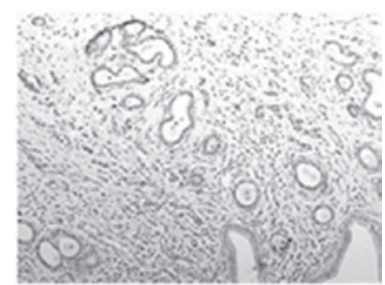

H

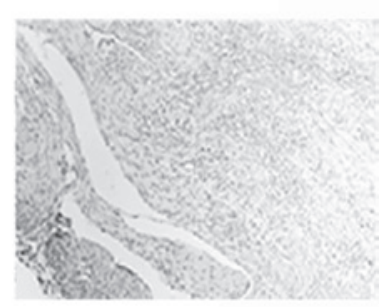

$\mathbf{L}$

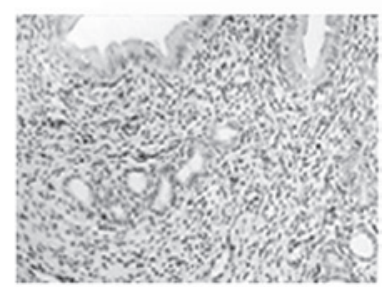

Figure 2. Immunohistochemistry staining showing the expression of the (A-D) estrogen receptor, (E-H) progesterone receptor and (I-L) fibronectin in the uterine tissue (scale bar, $50 \mu \mathrm{m}$ ) of the (A) normal, (B) pregnant control, (C) model and (D) Wujia Shenghua capsule treatment groups.

in the uterine tissues on day 14 of gestation when compared with the model group.

Excessive accumulation of FN and LM, the two main components of the stromal and underlying vascular extracellular matrices in the endometrium, may also promote endometrial hemorrhage by disturbing the balance of the extracellular matrix (23-25). The results of the present study demonstrated that WSC treatment notably reduced the plasma levels of FN and LM, and decreased the expression of FN in the uterine tissues on day 14 of gestation, as compared with the model group.

Increased plasma and blood viscosity is usually associated with dysfunction of the microcirculation, which may contribute to persistent damage of the uterine tissues (26). In the present study, the results demonstrated that the hemodynamic indexes were improved following treatment with WSC when compared with the model group, which may be an additional mechanism underlying the hemostatic effect of WSC.

In conclusion, based on the results of the present study, WSC was shown to exert an inhibitory effect on the uterine bleeding caused by medical abortion. In addition, the current study demonstrated a number of possible molecular and non-molecular mechanisms through which WSC may exert these effects, including modulation of the $\mathrm{E}_{2}, \mathrm{ER}, \mathrm{PR}, \mathrm{FN}$ and LM levels and improving the hemodynamic indexes. 


\section{Acknowledgements}

The study was supported by grants from the Heilongjiang Province Science and Technology Research Projects (no. GC10C208) and the Heilongjiang Province Administration of Traditional Chinese Medicine Topics (no. ZHY12-2077).

\section{References}

1. Bartz D and Goldberg A: Medication abortion. Clin Obstet Gynecol 52: 140-150, 2009.

2. Doraiswami S, Johnson T, Rao S, Rajkumar A, Vijayaraghavan J and Panicker VK: Study of endometrial pathology in abnormal uterine bleeding. J Obstet Gynaecol India 61: 426-430, 2011.

3. Spitz IM: Mifepristone: where do we come from and where are we going? Clinical development over a quarter of a century. Contraception 82: 442-452, 2010.

4. Chuang CH, Chang PJ, Hsieh WS, Tsai YJ, Lin SJ and Chen PC Chinese herbal medicine use in Taiwan during pregnancy and the postpartum period: a population-based cohort study. Int J Nurs Stud 46: 787-795, 2009.

5. Liao HL, Ma TC, Chiu YL, Chen JT and Chang YS: Factors influencing the purchasing behavior of TCM outpatients in Taiwan. J Altern Complement Med 14: 741-748, 2008.

6. Chang PJ, Tseng YC, Chuang CH, et al: Use of Sheng-Hua-Tang and health-related quality of life in postpartum women: a population-based cohort study in Taiwan. Int J Nurs Stud 47: 13-19,2010

7. Ho M, Li TC and Su SY: The association between traditional Chinese dietary and herbal therapies and uterine involution in postpartum women. Evid Based Complement Alternat Med 2011: 918291, 2011.

8. Geng F, Wang F, Zou T, et al: Rapid identification of the multiple absorbed bioactive components and metabolites in rat serum after oral administration of Wu-Jia Sheng-Hua capsule by UPLC-ESI-MS. J Anal Methods Chem 2013: 318961, 2013.

9. IRAC (Interagency Research Animal Committee).U.S. Government Principles for the Utilization and Care of Vertebrate Animals Used in Testing, Research and Training.Federal Register. Office of Technology Policy, Washington, pp 116-118, 1985.

10. Li X, Yuan FL, Zhao YQ, Lu WG, Li CW and He CH: Effect of leonurine hydrochloride on endothelin and the endothelin receptor-mediated signal pathway in medically-induced incomplete abortion in rats. Eur J Obstet Gynecol Reprod Biol 169: 299-303, 2013.
11. Cheng L: Medical abortion in early pregnancy: experience in China. Contraception 74: 61-65, 2006.

12. Li L, Zhou Z and Huang L: Abnormal expression of MMP-9 and imbalance of MMP-9/TIMP-1 is associated with prolonged uterine bleeding after a medical abortion with mifepristone and misoprostol. Acta Obstet Gynecol Scand 88: 673-679, 2009.

13. Li X, Yuan FL, Zhao YQ, et al: Effects of leonurine hydrochloride on medically induced incomplete abortion in early pregnancy rats. Eur J Obstet Gynecol Reprod Biol 159: 375-380, 2011.

14. Livingstone $M$ and Fraser IS: Mechanisms of abnormal uterine bleeding. Hum Reprod Update 8: 60-67, 2002.

15. Lockwood CJ: Mechanisms of normal and abnormal endometrial bleeding. Menopause 18: 408-411, 2011

16. Smith SK: Regulation of angiogenesis in the endometrium. Trends Endocrinol Metab 12: 147-151, 2001.

17. Vadlamudi RK, Balasenthil S, Broaddus RR, Gustafsson JA and Kumar R: Deregulation of estrogen receptor coactivator proline-, glutamic acid- and leucine-rich protein-1/modulator of nongenomic activity of estrogen receptor in human endometrial tumors. J Clin Endocrinol Metab 89: 6130-6138, 2004.

18. Im A and Appleman LJ: Mifepristone: pharmacology and clinical impact in reproductive medicine, endocrinology and oncology. Expert Opin Pharmacother 11: 481-488, 2010.

19. Chwalisz K, Perez MC, Demanno D, Winkel C, Schubert G and Elger W: Selective progesterone receptor modulator development and use in the treatment of leiomyomata and endometriosis. Endocr Rev 26: 423-438, 2005.

20. Clark TJ: Modern management of abnormal uterine bleeding. Obstetrician and Gynaecologist 11: 79, 2009.

21. Fraser IS, Hickey M and Song JY: A comparison of mechanisms underlying disturbances of bleeding caused by spontaneous dysfunctional uterine bleeding or hormonal contraception. Hum Reprod 11 (Suppl 2): 165-178, 1996.

22. Williams AR, Critchley HO, Osei J, et al: The effects of the selective progesterone receptor modulator asoprisnil on the morphology of uterine tissues after 3 months treatment in patients with symptomatic uterine leiomyomata. Hum Reprod 22: 1696-1704, 2007.

23. Evans J, Kaitu'u-Lino T and Salamonsen LA: Extracellular matrix dynamics in scar-free endometrial repair: perspectives from mouse in vivo and human in vitro studies. Biol Reprod 85: 511-523, 2011.

24. Frantz C, Stewart KM and Weaver VM: The extracellular matrix at a glance. J Cell Sci 123: 4195-4200, 2010.

25. Hickey $M$ and Fraser IS: The structure of endometrial microvessels. Hum Reprod 15 (Suppl 3): 57-66, 2000.

26. Lipowsky HH: Microvascular rheology and hemodynamics. Microcirculation 12: 5-15, 2005. 